\title{
RELATION BETWEEN FUSARIUM WILT DISEASE AND ACCUMULATION OF PHENOLIC COMPOUNDS WITHIN RESISTANT AND SUSCEPTIBLE TOMATO CULTIVARS
}

\author{
M. E. Selim ${ }^{(1)}$, Hala A. Mahdy ${ }^{(2)}$, G. A. Ahmed ${ }^{(3)}$, Abeer H. Makhlouf ${ }^{(1)}$ \\ (1) Agricultural botany Dept., Plant Pathol. Branch, Fac. Of Agric., Menoufiya University. \\ Egypt. \\ (2) Plant Pathology Res. Inst., Agric. Res. Center, Giza, Egypt.

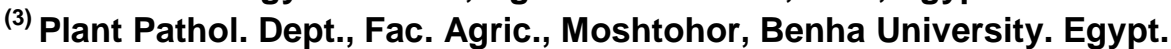

Received: Aug. 15, 2021

Accepted: Aug. 29, 2021

ABSTRACT: Wilting disease of tomato caused by Fusarium oxysporum f. sp. lycopersici, (FOL) is one of the most destructive diseases. This disease causes significant yield losses in Egypt. Ten Fusarium isolates were isolated from wilted tomato plants growing in El-Menoufia Governorate during 2020 growing season. The most virulent isolate (isolate No. 6) was tested for its virulence on ten tomato cultivars under greenhouse conditions. The cultivars were significantly varied in their susceptibility toward the tested virulent isolate. The most susceptible cultivar was Carmen F1cv as it recorded the highest value of infection (100\% and $96 \%)$ in seeds and seedlings experiments, respectively. On the other hand the results showed that Diamond Arwa cultivar was the most resistant tested cultivar where zero infection percentage was recorded on both seeds and seedling experiments. The chemical analysis using HPLC was conducted with the most susceptible tomato cultivar (Carmen) and the most resistant one (Diamond Arwa) one and three weeks post inoculation with pathogenic isolate of Fusarium. The results revealed that the accumulation of total phenolic compounds either in shoots or roots was higher three weeks after inoculation than one week post inoculation within the two tested cultivars. Remarkable that roots and shoots of most resistant cultivar tested recorded more total phenol concentrations rather than the susceptible one. Significant differences were detected among the resistant and the susceptible cultivars tested with the compounds detected at $21.2 \mathrm{~m} ; 26,2 \mathrm{~m}$ and 29.1 minute in both shoots and roots three weeks after pathogen inoculation which suggesting potential role of these particular chemicals in resistance mechanism toward Fusarium wilt disease within resistant tomato cultivars.

Key words: Fusarium wilt-HPLC-Phenolic compounds- Tomato

\section{INTRODUCTION}

Tomato (Lycopersicon esculentum Mill.) is systematically found in the Solanaceae family. It is considered economically the most important and popular vegetables throughout the world. Tomato is one of the most important produced and consumed agricultural products next to potato in Egypt and all over the world (Hafez et al., 2012). Many diseases affect quality and quantity of tomato and cause substantial economic loss (Pritesh \& Subramanian, 2011). The vascular wilt of tomato caused by Fusarium oxysporum f.sp. lycopersici (FOL), is one of the most destructive diseases in history, indicating significant yield losses (Anam et al., 2017 and Aleaghaee et al., 2018). FOL causing the symptoms of root rot, damping off, wilt diseases and death of the plants (AbuTaleb et al., 2011). In the last decade, Fusarium caused severe damage to tomato cultivars in Egypt (Sagitov et al., 2008). The dangerous of FOL is rising 
from its ability to survive for long periods of time under field conditions. Infection of FOL can occur from the germination of soil borne spores in the vicinity of growing roots, attachment to the root surface, penetration of the cortex of root and spreading of mycelium within the root vascular system. The fungus invades and colonizes the parenchyma of the dying tomato plant and sporulates on the plant surface (Michielse and Rep, 2009). Some isolates induce root-rot and vascular diseases on specific cultivars (Olivain et al., 1981 and Olivain et al., 2003) and classified into 120 formae speciales and races, based on the species of plant and cultivars they infect (Armstrong and Armstrong, 1981 and Alabouvette et al., 2001). Pathogenic isolates of $F$. oxysporum often display a high degree of host specificity (Sakai, 1998). Infection occurs when the pathogen penetrates in roots of the plant. The role of phenolic compounds in disease resistance mechanisms toward Fusarium infection is well known (Kalaichelvan and Nagarajan, 1992). The total phenol levels gave surely an increase in the capability of plants to defense against disease infection process and disease development (Ahmed 2005).

\section{MATERIALS AND METHODS}

This work was carried out in Faculty of Agriculture, Menoufia University, during 2020 growing season. Tomato seeds were obtained by Arkan agricultural projects development. Ten varieties of tomato plants (Diamond Arwa F1, Hybrid 71, Hybrid Karnak F1, Clara F1, Hybrid Amberial, Hybrid F16, K-186, Carmen F1, Staffie 409 and Jasper 3709) were investigated to determine the susceptibility and resistance potential to Fusarium oxysporum f.sp. lycopersici (FOL).
Samples collection and isolation of Fusarium oxysporum f.sp lycopersici (FOL):

Fusarium oxysporum f.sp. lycopersici (FOL) isolates were isolated from diseased tomato plants (12 weeks old) showing clear wilt symptoms especially, vesicles brown discoloration. Samples were collected from crop field of Sadat City, Menoufia governorate. Samples were taken in sterilized polythene bags (to avoid aerial contamination) separately. Roots and stem bases were first cut into small pieces, gently washed by running tap water to remove soil adhesive particles. The samples were surface sterilized by sodium hypochlorite (3\%) for $3 \mathrm{~min}$ and rinsed again with sterile distilled water, dried between sterilized filter paper (Mathur and Kongsdal, 2003). The sterilized small pieces were placed in Petri dishes containing Potato Dextrose Agar (PDA) with $300 \mathrm{mg} / \mathrm{L}$ of Streptomycin (Sigma). The plates were incubated at $25^{\circ} \mathrm{C}$ for 5 to 7 days.

\section{Purification and Identification of Fusarium oxysporum f.sp lycopersici (FOL):}

Identification of fungal cultures was carried out according to cultural and microscopical characteristics described by Booth (1971), Alexopoulos and Mims (1979), Ellis (1971), and Barnett and Hunter (1987). Purification of FOL was carried out, using both single spore and hyphal tip techniques (Hansen, 1926). According to the morphological characteristics of microconidia, macroconidia, phialides and chlamydospores (Summerell et al., 2003) Pure cultures of the obtained isolates were identified in laboratory of Faculty of Agriculture, Menoufia University. Pure cultures transferred to PDA medium slants and kept at $5^{\circ} \mathrm{C}$ for further studies. 


\section{Growth of tomatoes seed and seedling:}

For planting seeds, Pots $(20 \mathrm{~cm}$ in diameter) were sterilized by dipping in $5 \%$ formalin for 7 minutes and left for ten days until formalin evaporation. Pots were filled with the mixture of sterilized sand: clay: peat at rat $(1: 1: 1)$, FOL was sub-cultured on potato dextrose agar at $27 \mathrm{C}^{\circ}$. Each sterilized pot was inoculated with $5 \mathrm{ml}$ of FOL culture suspension $\left(10^{7}\right.$ $\mathrm{cfu} / \mathrm{ml}$ ) for two weeks to allow the fungus distribution into the soil (El-Khallal, 2007). All seeds were surface sterilized with $3 \%$ sodium hypochlorite solution for 3 min., rinsed in sterile distilled water, dried between folds of sterilized filter paper. Then all cultivars were planted with rate of five seeds/pot and five replicates for each cultivar were made before incubated at 12:12 hours light: dark cycle, at $25{ }^{\circ} \mathrm{C}$ for 15 days. The grown seeds were examined every day for the wilt disease.

For planting seedling, Clay loam soil was autoclaved twice at $121^{\circ} \mathrm{C}$ for an hour. Inoculum of FOL was prepared using sterilized Barley sand medium (75 $\mathrm{g}$ barley $+25 \mathrm{~g}$ sand $+100 \mathrm{ml}$ water); using $1000 \mathrm{ml}$ flasks. Flasks were incubated at $25^{\circ} \mathrm{C}$ for 2 weeks and shacked daily to allow all fungal growth. Sterilized soil was infested with isolate of FOL at the rate of $5 \%$ of soil weight. Two seedling plants (21 days old) were planting in each pot with five replicates for each cultivar. Potted soil kept under greenhouse conditions at $65 \%$ relative humidity, Three weeks post pathogen inoculation (6 weeks old tomato seedlings) of planted seedling, plants in each variety were individually observed for diseases scoring in each genotype and scored for typical wilt symptoms.

Disease severity (DS) was calculated using $0-4$ scale, $(0=$ asymptomatic, $1=$ yellowing, 2 = vascular discoloration, 3 = wilting, 4 = plant dead) according to Epp (1987) formula equation:

DS $=[($ ni $\times \mathrm{si}) /(\mathrm{N} \times \mathrm{S})] \times 100 \%$.

Where, ni: number of tomato plants with wilt symptoms, si: value of the score of symptoms, $\mathrm{N}$ : total number of tested tomato plants, and S: the highest value of score of symptoms (Cachinero et al., 2002). Overall responses of the tested tomato varieties against Fusarium wilt was established using the following criteria: $D S=0 \%$; immune, - DS = 1-20\%; resistant, $D S=21-40 \%$; moderately susceptible, DS = 41-70\%; susceptible, DS $=71-100 \%$; very susceptible (Dan Sudarsono, 2004).

Furthermore, percentage of infection (PI) was estimated after 21 days in seed experiment and after 60 days for seedling experiment according to this formula: $\mathrm{PI}=$ No. of diseased plants $\times 100 /$ Total No. of plants

\section{HPLC analysis:}

Chromatogram analysis of shoots and roots of two different tomato cultivars i.e. Diamond Arwa and Carmen was performed using high pressure liquid chromatogram (HPLC) according to modified methods of Selim et al., (2014). The HPLC apparatus, Agilent Technologies 1262 Infinity system, was preceded by an Eclipse plus ${ }^{\circledR} \quad \mathrm{C}_{18}$ reverse-phase guard column $(4.6 \times 10.0$ $\mathrm{mm}, 3.5 \mu \mathrm{m})$. The HPLC system consisted of Pump unit, diode array detector, and auto sampler (1260, Agilent Technologies) which were controlled by Chemo Station for LC 3D system. Before samples were injected, the column had been equilibrated with $90 \%(\mathrm{v} / \mathrm{v})$ water (solvent $A$ ) and $10 \%$ acetonitril (solvent B). After injection, the samples were eluted at a flow rate of $1.0 \mathrm{ml} \mathrm{min-1}$ using an isocratic flow of $90 \%$ solvent $A$ and $10 \%$ solvent $B$ for 2 min, a linear gradient to $10 \%$ solvent $A$ and $90 \%$ solvent $B$ for $28 \mathrm{~min}$, followed by an isocratic flow for 5 
min with $90 \%$ solvent B. For conducting HPLC analysis, $1.5 \mathrm{~g}$ of fresh shoots and roots were collected from three replicates of Diomond Arwa and Carmen plants inoculated with Fusarium oxysporum one week after inoculation. Fresh shoots and roots were immediately freeze-dried using liquid nitrogen. The freeze-dried materials were mixed thoroughly individually with $15 \mathrm{ml}$ of ethyl acetate in plastic test tubes for $5 \mathrm{~min}$. After separation, the suspension was filtrated into new tubes through two cotton layers and evaporated under vacuum to completion. The extracted compounds were then dissolved in $150 \mu \mathrm{l}$ absolute methanol and $50 \mu \mathrm{l}$ of each chemical extraction was injected into HPLC. Spectral analysis was conducted to compare the detected peaks with similar retention times in all extractions. The same procedure was used for the chromatogram analysis of shoots and roots of both two cultivars three weeks after pathogen inoculation.

\section{Statistical analysis:}

Data were statistically analyzed according to standard analysis of variance by a one way ANOVA with the software statgraphics (Statistical Graphics. Crop, Rockville, MD), Variance homogeneity for all treatments was confirmed by the Bartlett test. The comparison between means was carried out by Duncan's Multiple Range Test (Duncan, 1955) as given in the figures.

\section{RESULTS AND DISCUSSION}

Identification and morphological characteristics of the isolates:

The isolated fungi were identified as Fusarium oxysporum f. sp. Iycopercisi (FOL). Ten isolates of (FOL) were observed and isolate No. 6 was chosen for this study as it was considered the most virulent isolate and it produced more spores.

\section{Determination of disease severity in tested tomato cultivars:}

Data presented in Fig. 1 show that, most of inoculated tested cultivars exhibited wilt symptoms. The highest disease severity (DS) values were observed with Carmen F1, Hybrid 71 and Staffie 409 cvs. $(100 \%, 96 \%$ and $92 \%$ respectively) and (96\%, $90.4 \%$ and $91.2 \%$ respectively) in seed and seedlings experiments, respectively. In contrary, the results showed that both of Diamond Arwa F1 and Clara F1 cvs. recorded the lowest DS values $(0 \%)$ compared with the other tested cultivars in both seeds and seedlings experiments (fig1). Moreover, moderate DS values ranged from $15-45 \%$ were recorded on three different tested tomato cultivars i.e. K-186, Hybrid F16 and Hybrid Am in both seeds and seedlings experiments (Fig.1).

Determination of percentage of infection within tested tomato cultivars:

Results shown in Fig. 2 clear that most of the tested cultivars had significant susceptibility to Fusarium oxysporum pathogen (FOL). The highest infection percentage (100\%) was recorded on Carmen F1cv. It was considered the most susceptible tested cultivar either in seed or seedlings experiments among the all 10 tested cultivars (Fig. 3). Moreover, the lowest value of $\mathrm{PI}(0 \%)$ was observed with Jasper3709 and Diamond Arwa cultivars and therefore they were considered the most resistant cultivars toward Fusarium pathogen among the all tested cultivars where no yellowing, vascular discoloration, wilting symptoms or plant dead were recorded in either seed or seedlings experiments (Fig. 4). 
Relation between fusarium wilt disease and accumulation of phenolic

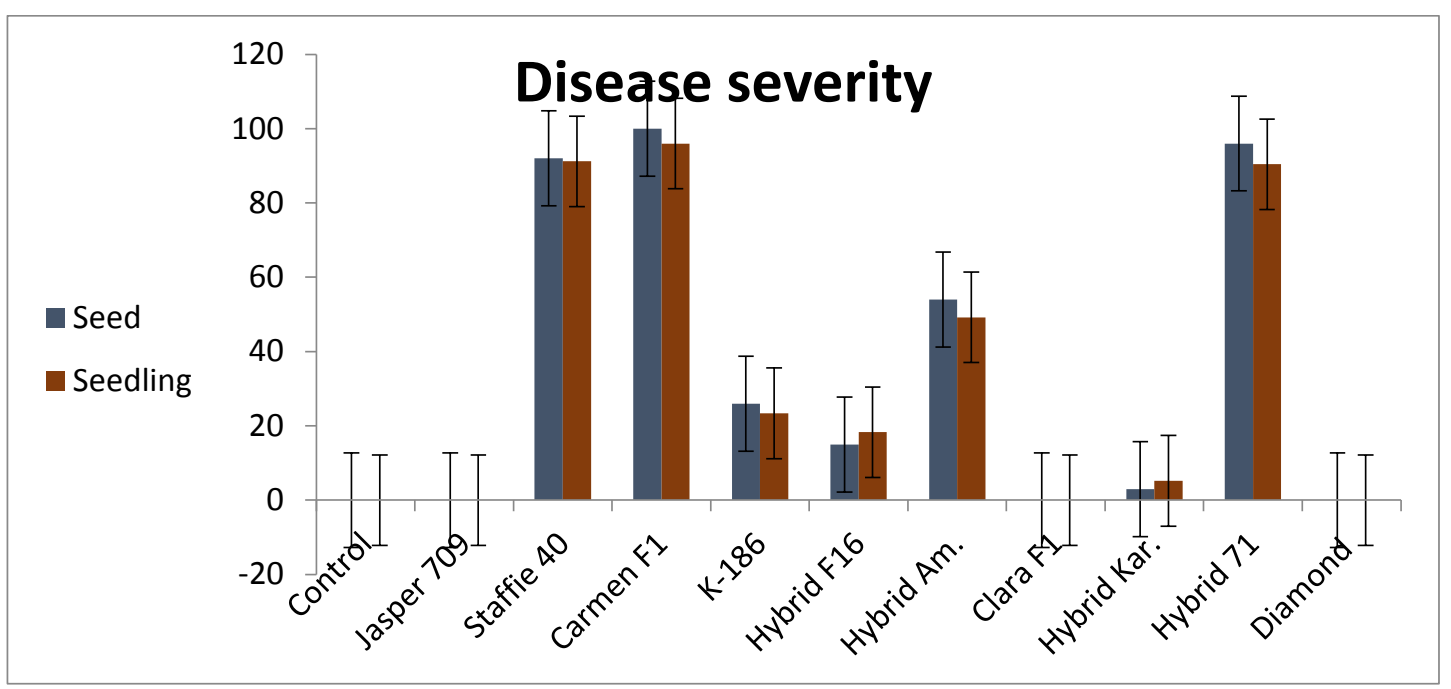

Figure 1: Disease severity of Fusarium wilt disease recorded with $\mathbf{1 0}$ tomato cultivars to in seeds and seedlings experiments.

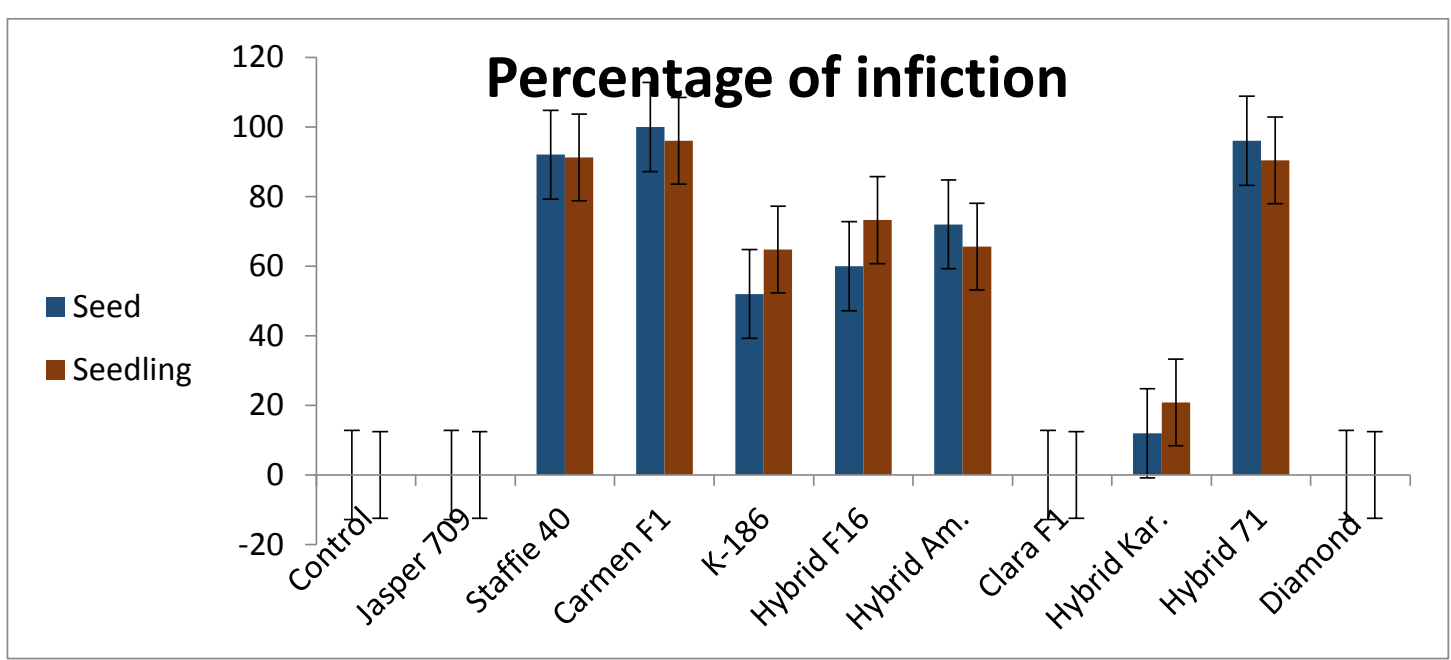

Figure 2: Percentage of infection (PI) in tested tomato cultivars to inoculation with the tested FOL isolate.

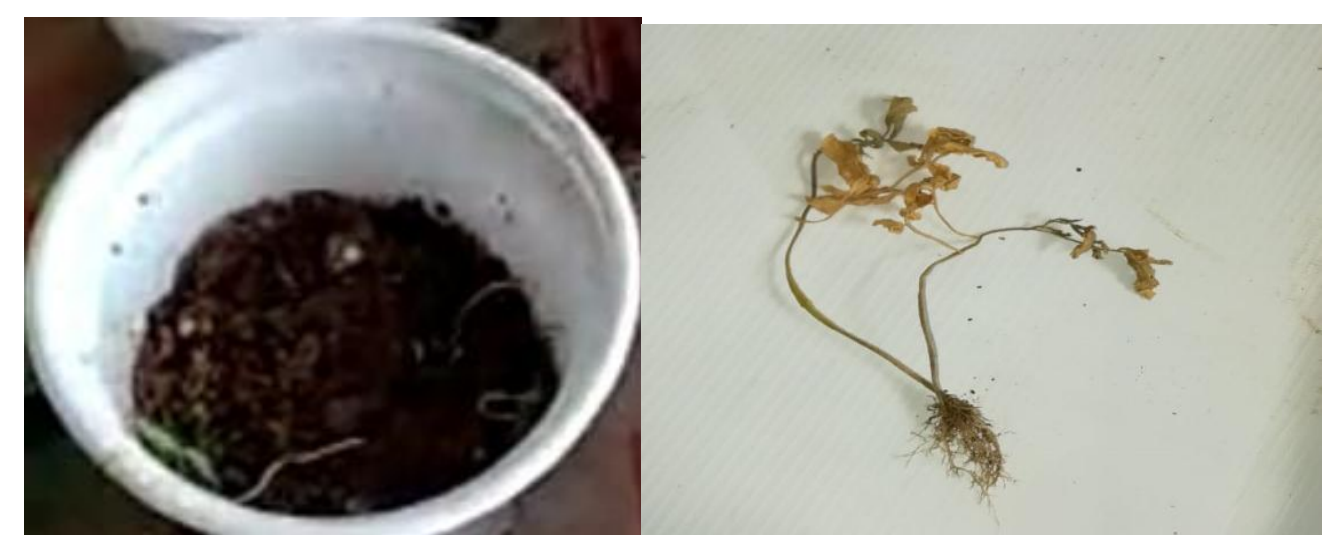

Figure 3: Symptoms of infection with Carmen cultivar in seed and seedlings experiments 


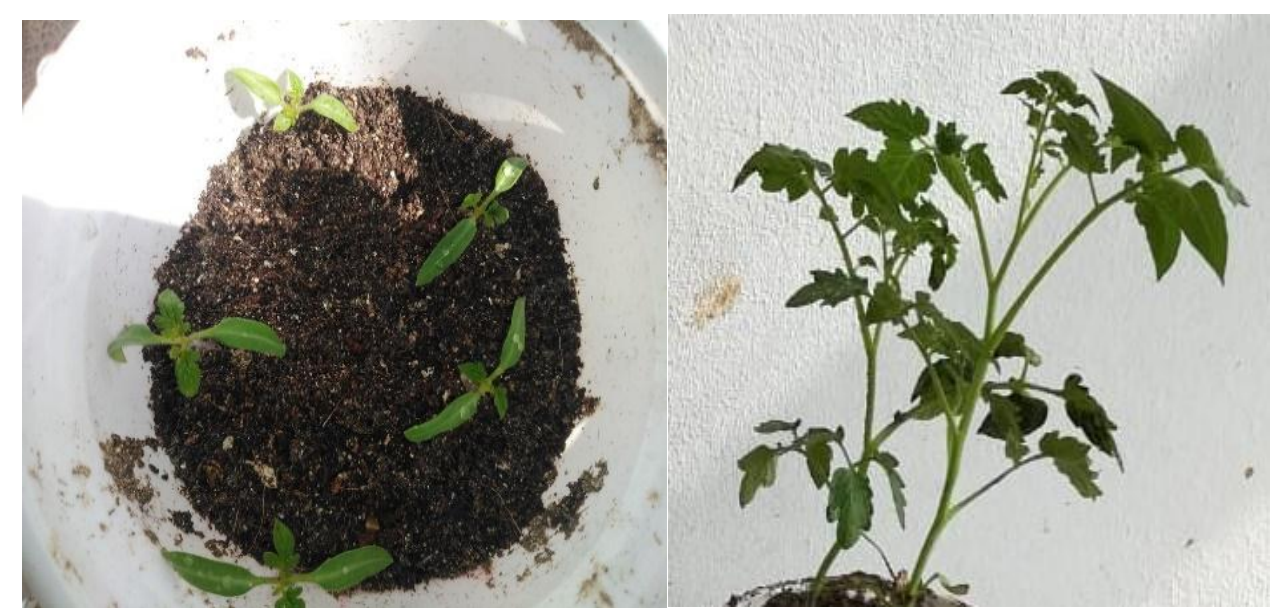

Figure 4: Symptoms of infection with Diamond Arwa cultivar in seed and seedlings experiments

\section{Chromatogram analysis using HPLC: (270nm)}

In presented study, a mixture of different chemically active compounds, i.e., acetone-DNPH, acrolein-DNPH, 2,5dimethylbenzaldehyde-DNPH, formaldehyde-DNPH, isovaleraldehydeDNPH and propionaldehyde-DNPH, were used as references to compare the spectral pattern of obtained peaks one week and three weeks after Fusarium inoculation within roots and shoots of the two cultivars tested (Diamond Arwa and Carmnen). The chemical analysis using HPLC revealed that either tested susceptible (Carmen) and resistant (Diamond Arwa) tomato cultivars in this study responded chemically to $F$. oxysporum inoculation. Thus, the inoculation of Fusarium pathogen resulted in accumulating of different certain compounds in both shoots and roots of infested plants.

The accumulation of chemical compounds in roots and shoots of the most tolerant tomato cultivar tested (Diamond Arwa F1 cvs.) and the most sensitive tomato cultivar (Carmen F1cv) was determined one week and three weeks post Fusarium inoculation using the array detector chromatogram at a wave length of $270 \mathrm{~nm}$. The area under the curve of the peaks with retention time of $19.0 ; 21.2 ; 24.2 ; 25.8 ; 26.2 ; 28.2$; and 29.1 minutes was calculated. Similarity of the peaks detected with similar retention times within the two tested tomato cultivars was also analysed using spectral analysis.

The results show that one week after Fusarium inoculation, the accumulation of the chemical compounds generally and particularly with those detected at retention time of $19.0 ; 21.2 ; 24.2 ; 25.8$; 26.2; 28.2; and 29.1 minutes was higher $(535,85 \mathrm{mAu} / \mathrm{g})$ within shoots and leaves of cultivar Diamond Arwa than within cultivar Carmen (474,2 mAu/g), (Fig. 5). Remarkable, two fold increase of concentration of the compound that detected within retention time of $\mathbf{2 6 . 2}$ minute was recorded with the tolerant cultivar tested (Diamond Arwa), (Fig. 5). 


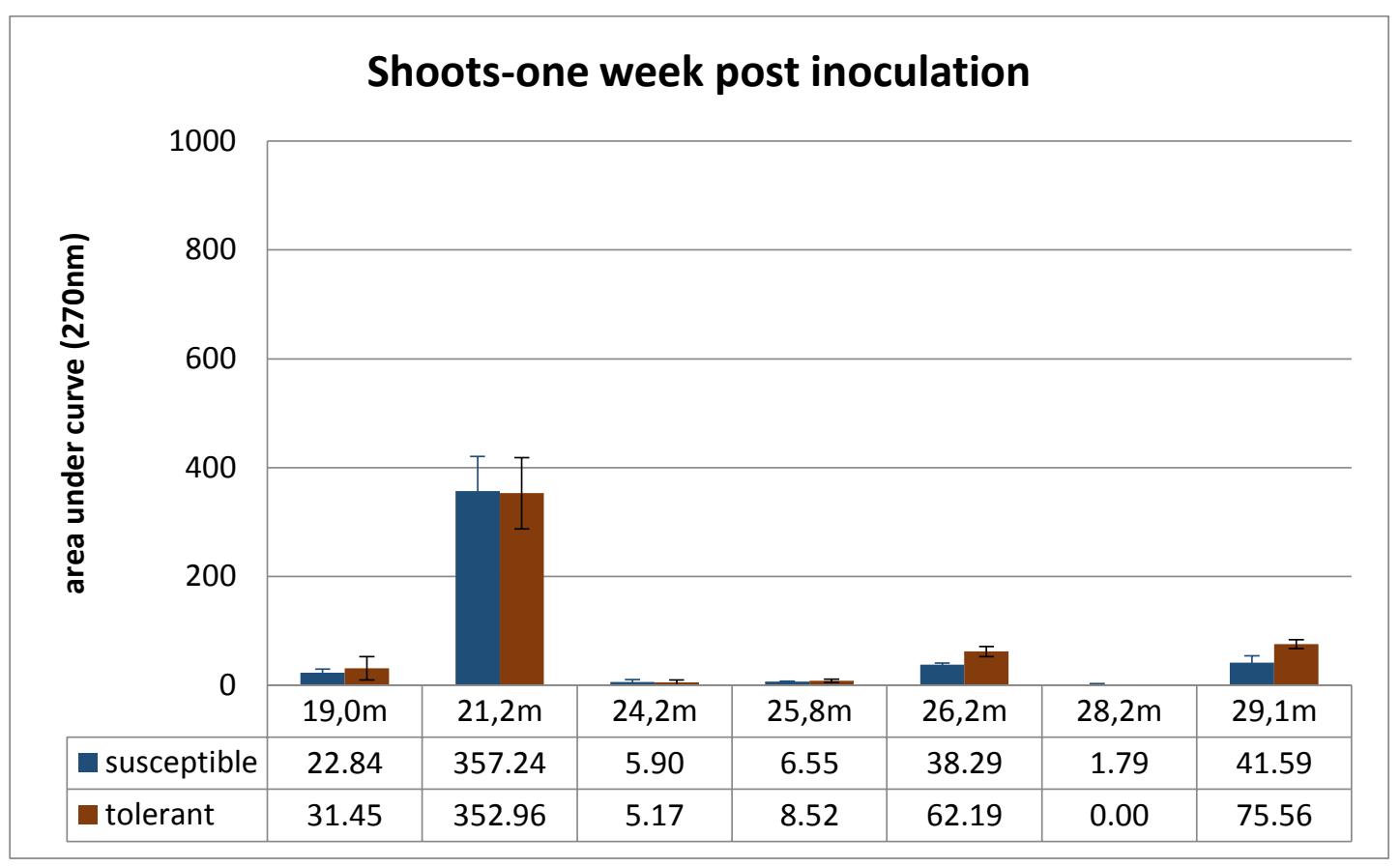

Figure 5: Accumulation of the compounds detected with the retention time of 19.0; 21.2; 24.2; 25.8; 26.2; 28.2; and 29.1 minute at $270 \mathrm{~nm}$ in leaves and shoots obtained from tomato cultivars Diamond Arwa (resistant) and Carmen (susceptible) one week after Fusarium inoculation.

Similar results were recorded again with aspect to the accumulation of these certain compounds in roots of both Cultivars tested (Fig. 6). Thus, the total concentration of the detected chemicals substrates was recorded up to $384 \mathrm{mAu} / \mathrm{g}$ and $275 \mathrm{mAu} / \mathrm{g}$ within roots of Diamond Arwa and Carmne cultivars, respectively (Fig. 6).

Three weeks after Fusarium inoculation, HPLC chromatogram analysis of foliar system of the two tested tomato cultivars showed that the accumulation of the investigated chemical compounds was increased generally comparing to the accumulation of same compounds recorded one week after Fusarium application (Fig. 7).

Moreover, significant differences were recorded among cultivar Diamond Arwa and cultivar Carmen with aspect to specific compounds that detected at the retention time of $21.2 ; 26.2$; and 29.1 minute (Fig 8).

As observed with foliar system analysis, the chemical profiling of root systems three weeks after Fusarium inoculation, demonstrated that the accumulation of total screened chemical substrates increased in root system of both two cultivars comparing to the concentration of same chemical substrates recorded one week post inoculation. The total concentrations of detected chemical substances recorded up to 918 and $730 \mathrm{mAu} / \mathrm{g}$ with Diamond Arwa and Carmen cultivars, respectively (Fig. 9). Noteworthy, significant differences were detected again among the two tested cultivars with aspect to the accumulation of detected compounds with retention time of 21.2; 26.2 and 29.1 minute at $270 \mathrm{~nm}$ array (Fig. 10). 
M. E. Selim, et al.,

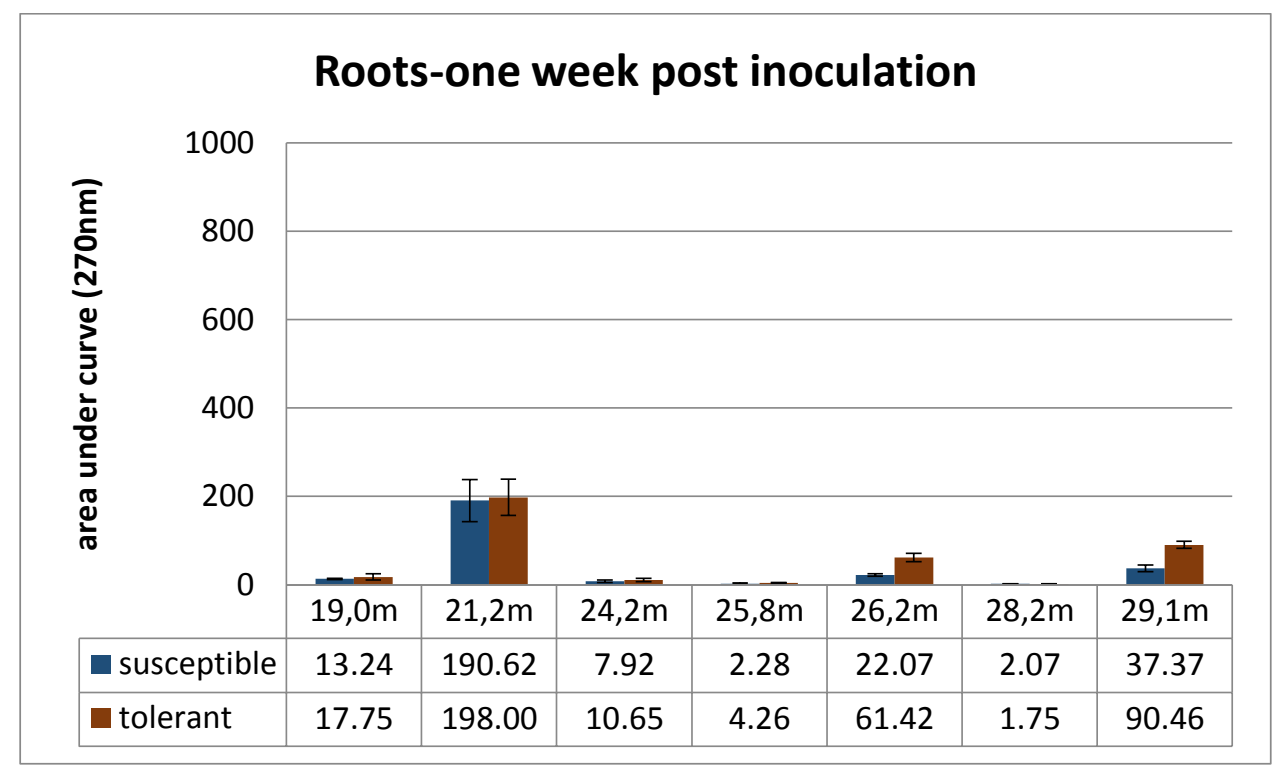

Figure 6: Accumulation of the compounds detected with the retention time of 19.0; 21.2; 24.2; 25.8; 26.2; 28.2; and 29.1 minute at $270 \mathrm{~nm}$ in roots obtained from tomato cultivars Diamond Arwa (resistant) and Carmen (susceptible) one week after Fusarium inoculation.

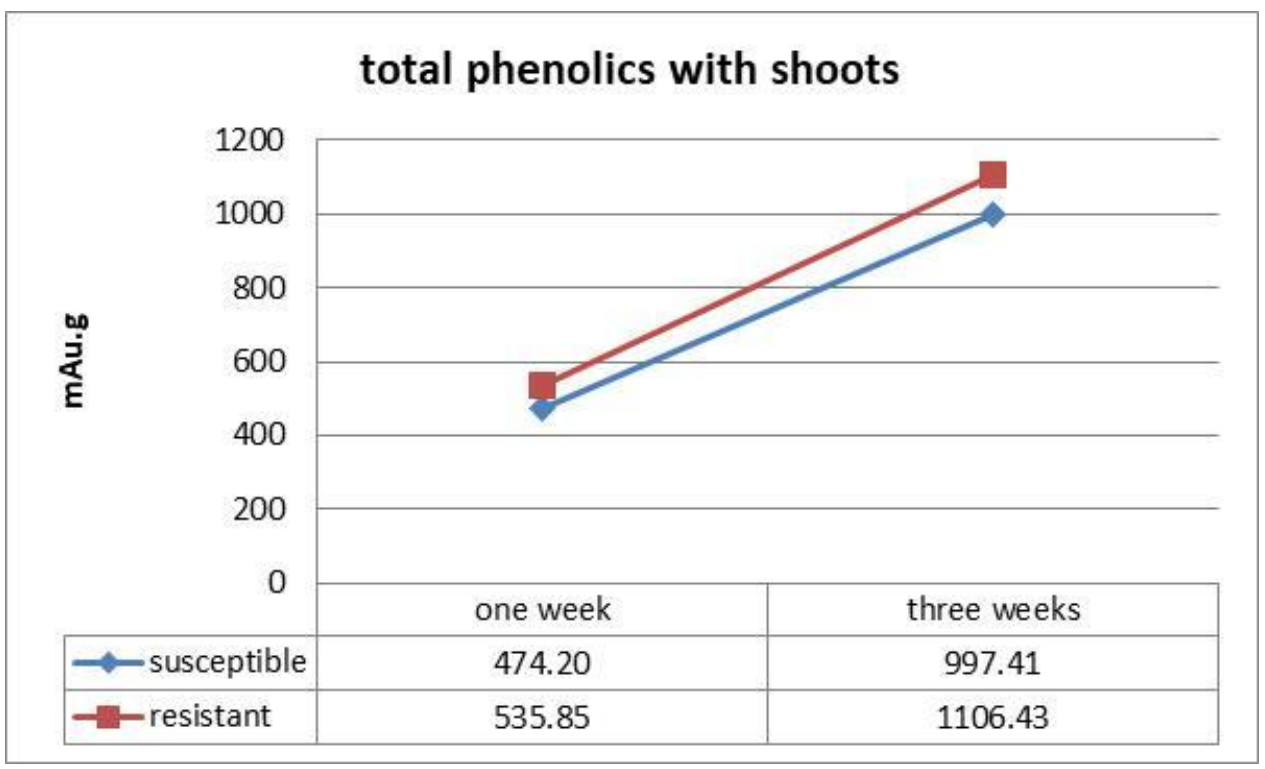

Figure 7: Total phenolic compounds accumulated one and three weeks post inoculation with virulent Fusarium oxysporum isolate in shoots of two different tomato cultivars. 


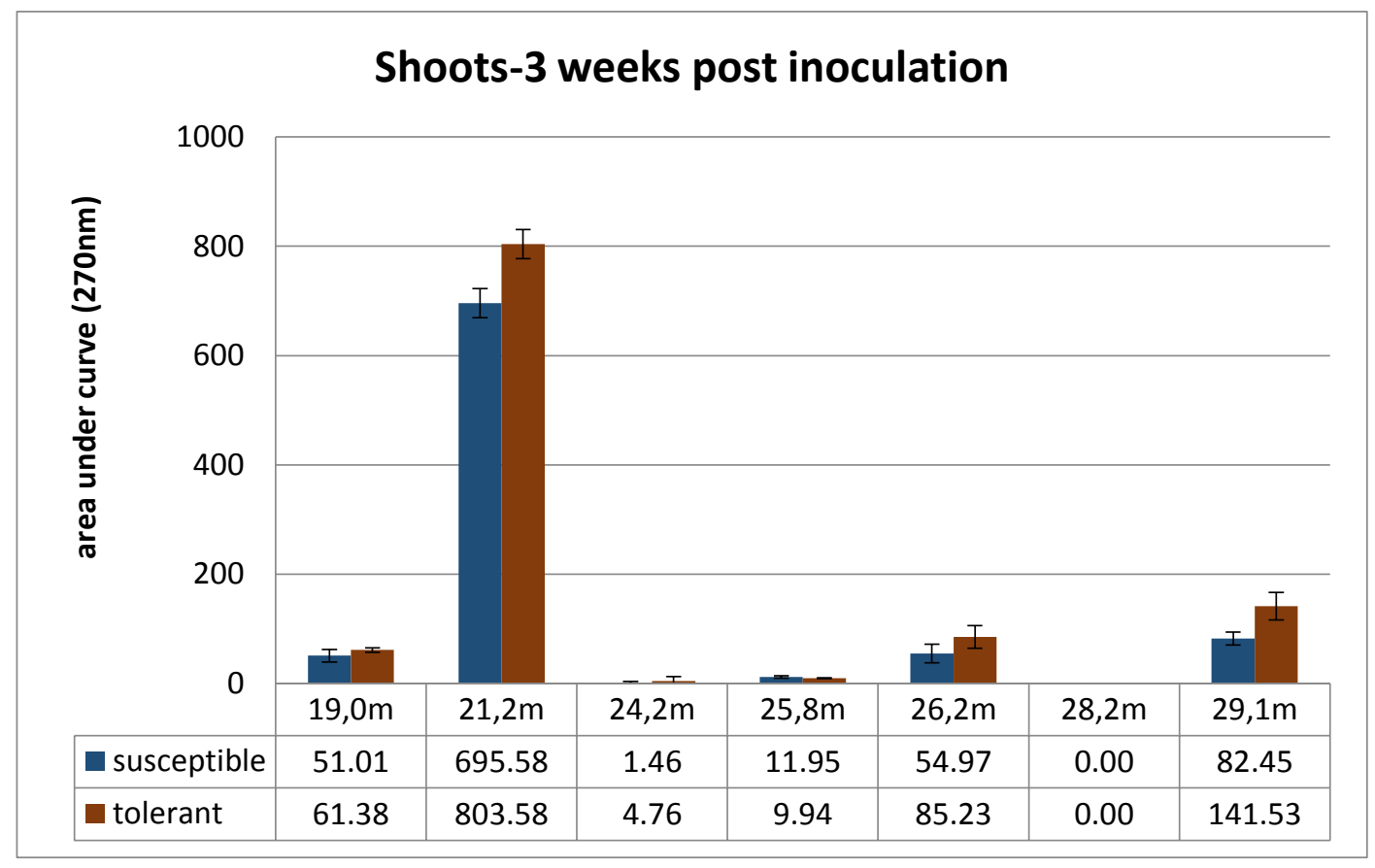

Figure 8: Accumulation of the compounds detected with the retention time of 19.0; 21.2; 24.2; 25.8; 26.2; 28.2; and 29.1 minute at $270 \mathrm{~nm}$ in leaves and shoots obtained from tomato cultivars Diamond Arwa (resistant) and Carmen (susceptible) three weeks after Fusarium inoculation.

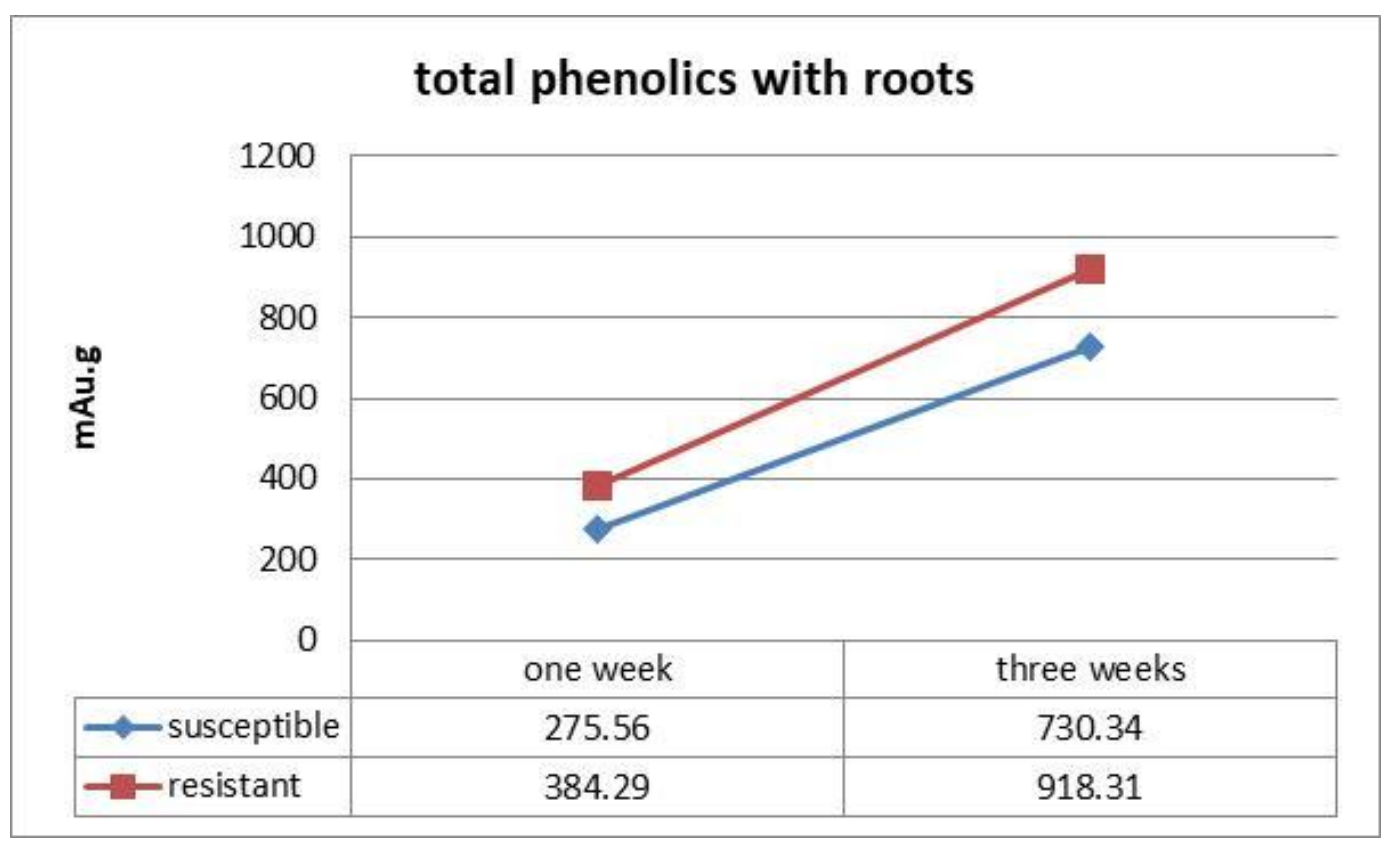

Figure 9. total phenolic compounds accumulated one and three weeks post inoculation with virulent Fusarium oxysporum isolate in roots of two different tomato cultivars. 


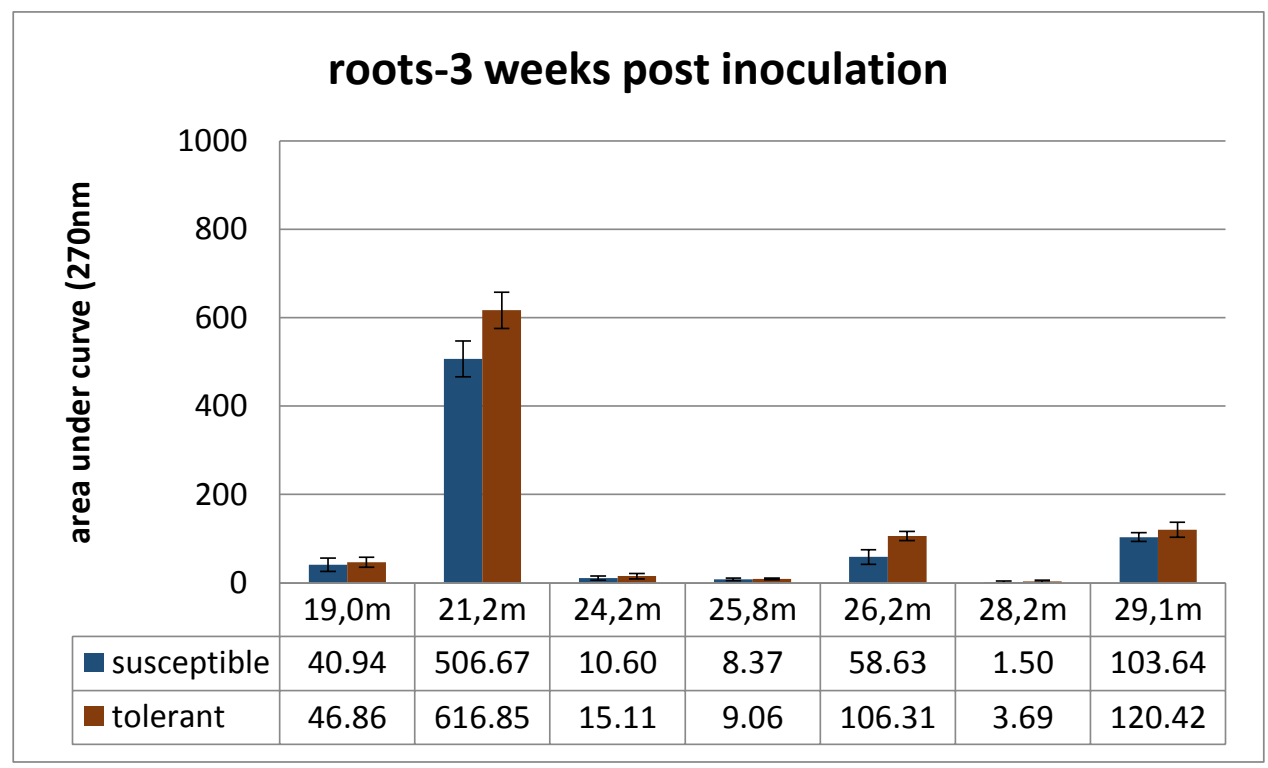

Figure 10: Accumulation of the compounds detected with the retention time of 19.0; 21.2; 24.2; $25.8 ; 26.2 ; 28.2$; and 29.1 minute at $270 \mathrm{~nm}$ in roots obtained from tomato cultivars Diamond Arwa (resistant) and Carmen (susceptible) three weeks after Fusarium inoculation.

These results are consistence with Zacares et al., (2007), who surveyed metabolites of the phenylpropanoid pathway using HPLC of extracts from tomato plants challenged with Pseudomonas syringe and reported that the bacterial infection induced the systemic plants resistance and at the meanwhile increased significantly the accumulation of a set of four major compounds detected with retention time of (12.5 $\mathrm{min}, 12.7 \mathrm{~min} ., 13.2 \mathrm{~min}$. and 13.6 $\mathrm{min}$. at $280 \mathrm{~nm}$ wave length). They added also not all chemical compounds were be able to identify due to the irregularities in separation process or because these compounds were invisible in the range of the detector detection. Similar results were reported by Selim et al., (2014) who found that increasing the accumulation of different biochemical active compounds, which were alone or in combination, resulted in improving the resistance potential of tomato plants toward bio-trophic pests.
In conclusion, significant differences between resistant and susceptible tomato cultivars toward Fusarium wilt disease in accumulation and concentrations of phenolic compounds within roots and shoots system were recorded which pointing to potential role of these chemical substances in controlling Fusarium infection on tomato plants. Further studies concerning with isolation, fractionation and identifications of these varied compounds that particularly detected at retention time of 21.2; 26,2 and 29,1 minute are needed to infer size whether these compounds alone or in combinations are involving in interaction between virulent Fusarium oxysporum and tomato Fusarium wilt resistant cultivars.

\section{REFERENCES}

Abu-Taleb, M. Amira, Kadriya, El-Deeb and Fatimah and O. Al-Otibi (2011). Assessment of antifungal activity of Rumex vesicarius $L$. and Ziziphus spina-christi (L.) wild extracts against 
two phytopathogenic fungi. Afr. J. Microbiol. Res, 5(9):1001-1011.

Ahmed, G.A. (2005). Using plant extracts to control powdery mildew disease that attack cucumber plants under protected houses. M. Sc. Thesis Fac. of Agric., Moshtohor. Zagazig Univ., Benha branch. Egypt.

Alabouvette, C., X. Edel, P. Lemanceau, C. Olivain, G. Recorbet and C. Steinberg (2001). Diversity and interactions among isolates of Fusarium oxysporum: Application and biological control. In: Biotic Interactions in Plant-pathogen Associations, pp: 131-157. Jeger, M.J. and N.J. Spence (eds.). CAB International, Wallingford, UK

Aleaghaee, S., S. Rezaee, M. Ebadi and H. R. Zamanizadeh (2018). The efficacy of some native Trichoderma isolates in induction of resistance in tomato against Fusarium oxysporum f.sp. lycopersici, the causal agent of fusarium wilt disease. [Persian] Applied Entomology and Phytopathology; 85(2): 219-233

Alexopoulos, C. J. and C. W. Mims (1979). Introductory Mycology. John Willy and Sons. Inc., New York, Chichester Brisbance, Toronto, Third Edition, 632.

Anam Moosa, Sahi, S. T., Imran-ul-Haq, Ayaz Farzand, S. A. Khan and Javaid Khushboo, (2017). Antagonistic potential of Trichoderma isolates and manures against fusarium wilt of tomato. International Journal of Vegetable Science; 23(3): 207-218.

Armstrong, G.M. and J.K. Armstrong (1981). Formae speciales and races of Fusarium oxysporum causing wilt diseases, In: Fusarium: Diseases,Biology and Taxonomy, pp: 391-399. Nelson, P.E., T.A. Toussoun and R. Cook (eds.). The Pennsylvania State University Press, UK
Barnett, H. L. and B. B. Hunter (1987). Illustrated genera of imperfect fungi.4th Edition. Burgess Publishing Company, Minneapolis, MN, 218 pp

Booth, C. (1971). The genus Fusarium. The Commonwealth Mycological Institute Kew, Surrey, England, 237pp.

Cachinero, J.M., A. Hervas, R.M. JimenezDiaz and M. Tena (2002). Plant defence reactions against Fusarium wilt in chickpea induced by incompatible race 0 of Fusarium oxysporum f.sp. ciceris and non-host isolates of $F$. oxysporum. Plant. Pathol., 51: 765776

Dan Sudarsono (2004). Metode Inokulasi dan Reaksi Ketahanan 30 Genotipe Kacang Tanah terhadap Penyakit Busuk Batang Sclerotium. Hayati,11: 53-58

Duncan, D. B. (1955). Multiple range and multiple F tests, Biometrics 11, 1-42.

El-Khallal, S. M., 2007. Induction and modulation of resistance in tomato plants against Fusarium wilt disease by bioagent fungi (Arbuscular mycorrhiza) and/or hormonal elicitors (jasmonic acid \& salicylic acid): 1Changes in growth, some metabolic activities and endogenous hormones related to defence mechanism. Australian Journal of Basic and Applied Sciences, 1(4): 691-705.

Ellis, M. B. (1971). Dematiaceous Hyphomycetes. Commonwealth Mycological Institute, Kew, England.608 pp.

Epp, D. (1987). Somaclonal variation in bananas: a case study with Fusarium wilt. In: Persley GJ, De Langhe EA (eds) Banana and plantain breeding strategies. ACIAR Proc No 21 Canberra, pp 140-150

Hafez, E. E., M. M. Balbaa, S. S. A. Kabeil, M. A. El-Saadani and S. A. Ahmed, 2012. Molecular studies on the biocontrol effect of Trichoderma viride 
and Bacillus subtilis on Fusarium oxysporum and Rhizoctonia solani infected tomato plants. World Applied Sciences Journal; 19(1): 89-99.

Kalaichelvan, P.T. and G. Nagarajan (1992). A fungitoxic alkaloid from Crotalaria paleda. Indian Phytopathol., 45 (2): 252-253.

Mathur, S.B. and O. Kongsdal (2003). Common laboratory seed health testing methods for detecting fungi. ISTA, Switzerland.

Michielse, C.B. and M. Rep (2009). Pathogen profile update: Fusarium oxysporum. Mol. Plant Pathol. 10, 311-324.

Olivain, C., C. Humbert, J. Nahalkova, J. Fatehi and J.K. Armstrong (1981). Formae speciales and races of Fusarium oxysporum causing wilt diseases. In: Fusarium: Diseases, Bbiology, and Taxonomy, pp: 391399. Nelson, P.E., T.A. Toussoun and R.J. Cook (eds.). Pennsylvania State University Press, University Park and London

Olivain, C., S. Trouvelot M. Binet, C. Cordier A. Pugin and C. Alabouvette (2003). Colonization of flax roots and early physiological responses of flax cells inoculated with pathogenic and non-pathogenic isolates of Fusarium oxysporum. Appl. Environ. Microbiol., 69: 5453-5462
Pritesh, P. and R. B. Subramanian (2011). PCR based method for testing Fusarium wilt resistance of tomato. African Journal of Basic and Applied Sciences,3, 219-222.

Sagitov, A.O., G.M. El-Habbaa and I.A. ElFiki (2010). Sensitivity of seven tomato cultivars to Fusarium wilt under glasshouse conditions in Kazakhstan. Egypt. J. Phytopathol., 38 (1-2): 89-97.

Sakai, K. (1998). Resistance of tomato cultivars to fusarium wilt (race 2). Bulletin of the Saitama Horticu. Exp. Station, 21: 27-40

Selim, M. E., M. E. Mahdy, Mervat E. Sorial and R. A. Sikora (2014). Biological and chemical dependent systemic resistance and their significance for the control of rootknot nematodes. Nematology. 16(8): 917:927.

Summerell, B. A., B. Salleh and J. F. Leslie (2003). A utilitarian approach to Fusarium identification. Plant Disease 87: 117-128.

Zacares, L., M.P. Lopez-Gresa, J. Fayos, J. Primo, J.M. Belles and V. Conejero (2007). Induction of pCoumaroyldopamine and Feruloyldopamine, two novel metabolites, in tomato by the bacterial pathogen Pseudomonas syringae. Molecular Plant-Microbe Interactions 20, 1439-1448. 
العلاقة بين مرض الذبول الفيوزاريومى وتراكم المركبات الفينولية داخل أصناف الطماطر المقاومة والحساسة

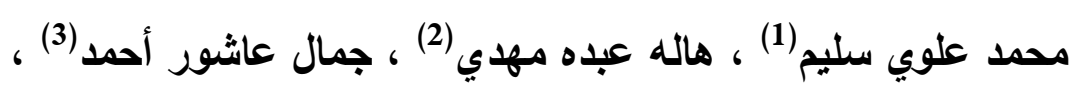

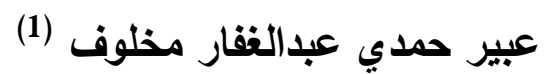

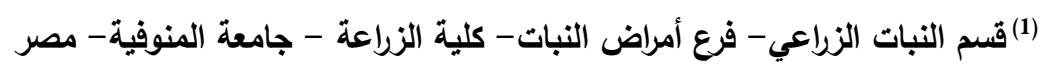

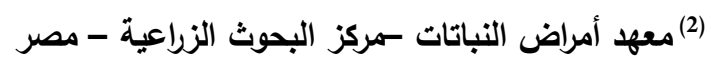

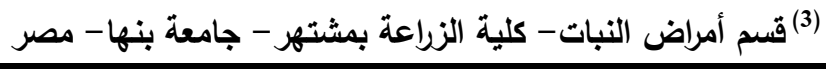

الملخص العربي

يُعد مرض ذبول الطماطم المتسب عن الفطر Fusarium oxysporum f. sp. lycopersici (FOL) هو أحد

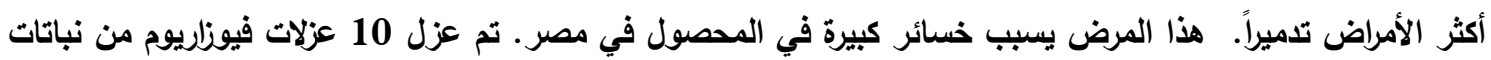

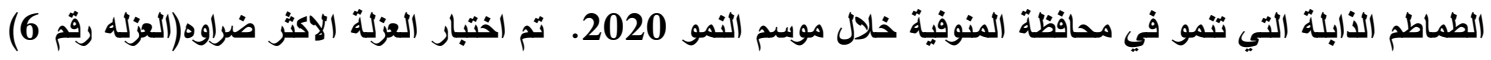

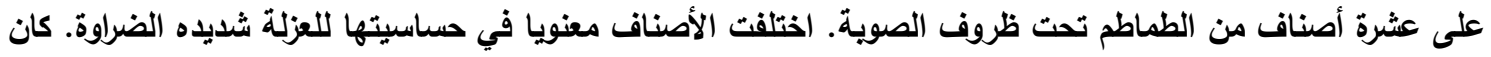

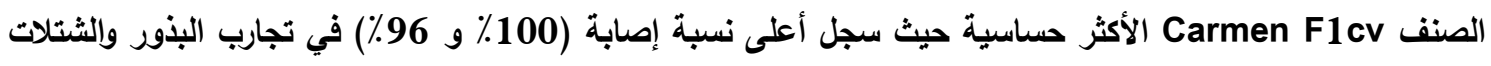

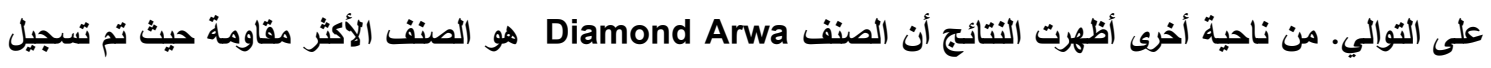

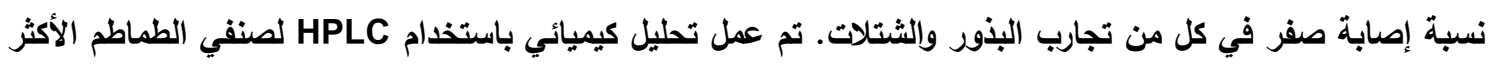

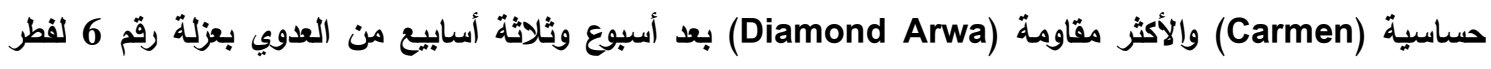

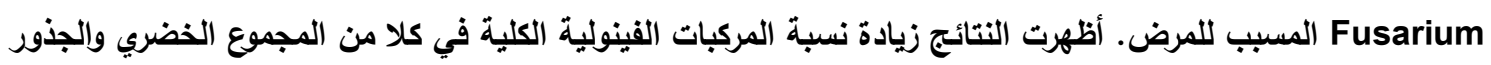

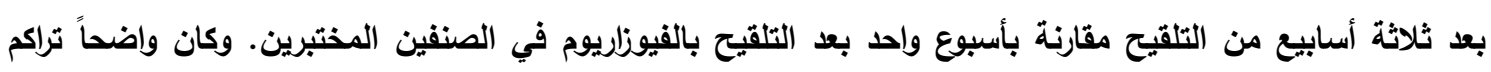

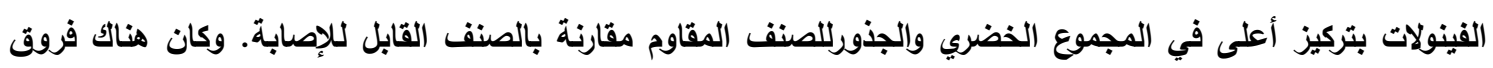

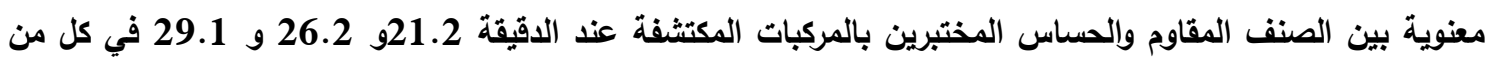

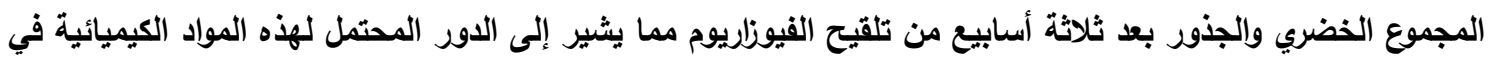
مقاومة مرض الذبول الفيوزاريومي في أصناف الطماطم المقاومة.

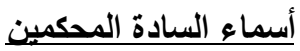

كلية الزراعة - جامعة كفر الثيخ

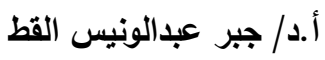

كلية الزراعة - جامعة المنوفية أ.د/ السعيد زكى خليفــــه. 